\title{
ЗАЛОГ ЦИФРОВЫХ ПРАВ КАК СПОСОБ ОБЕСПЕЧЕНИЯ ИСПОЛНЕНИЯ ОБЯЗАТЕЛЬСТВ СУБЪЕКТОВ МСП
}

\section{PLEDGE OF DIGITAL RIGHTS TO ENSURE THE FULFILLMENT OF OBLIGATIONS OF SMALL AND MEDIUM-SIZED COMPANIES}

D. Zyulkov

Summary. The article analyzes digital rights as an object of ensuring the fulfillment of obligations in lending to SMEs. The article examines "tokens", "big data", "social media accounts", "digital content" and "domain names", their legal nature, the possibility of transferring them as collateral, and the practical problems that arise when transferring them to a lender in case of default. Attention is drawn to the fact that digital rights as objects of enforcement of obligations have property value and are of interest to participants in civil turnover. Currently, the companies present tools for tracking the performance of obligations and the implementation of the forced transfer of digital rights to the pledgee.

Keywords: collateral, collateral, tokens, big data, social media accounts, digital content, domain names.
$\Pi$ остоянное развитие технологий, приводит к появлению новых предпринимателей, которые начинают свою деятельность с создания небольших компаний. Ограниченность их ресурсов, отсутствие опыта ведения бизнеса и необходимых знакомств приводит к замедлению внедрения инноваций в нашу повседневную жизнь.

Несмотря на то, что у всех есть доступ в интернет, в котором при помощи различных краудфандинговых площадок можно рассказать миру о своей идее и привлечь денежные средства для ее осуществления, остро стоит проблема привлечения кредитных ресурсов для малых и средних субъектов инновационной и высокотехнологичной предпринимательской деятельности.

Зачастую у основателя высокотехнологичного стартапа в активах нет ничего кроме результата интеллектуальной деятельности в виде прототипа, или даже простой концепции. При этом сама идея, наработанный опыт ее создателей, результаты их деятельности в виде опытных образцов, в будущем могут иметь большую ценность как для частных компаний и государства, так и для граждан в целом.

\author{
Зюльков Дмитрий Сергеевич \\ Аспирант, Финансовый университет при \\ Правительстве Российской Федерации (г. Москва) \\ dmitryzyulkov@gmail.com
}

Аннотация. В статье проводится анализ цифровых прав как объекта обеспечения исполнения обязательств при кредитовании субъектов МСП. Исследуются «токены», «большие данные», «аккаунты в социальных сетях», «контент в цифровой форме» и "доменные имена», их правовая природа, возможность передачи в залог и практические проблемы, возникающие при передаче кредитору в случае неисполнения обязательств. Обращается внимание на тот факт, что цифровые права как объекты обеспечения исполнения обязательств имеют имущественную ценность и представляют интерес для участников гражданского оборота. В настоящее время, компаниями представлены инструменты по отслеживанию исполнения обязательства и осуществлению принудительной передачи цифровых прав залогодержателю.

Ключевые слова: обеспечение исполнение обязательств, залог, токены, большие данные, аккаунты в социальных сетях, контент в цифровой форме, доменные имена.

Стремительная цифровизация человеческих отношений повлияла на взгляд того, что является ценностью, приносящую экономическую выгоду. Раньше, в большинстве случаев активом компании были средства производства, сотрудники, ноу хау, которые позволяли удовлетворять запросы потребителей, но в связи с глобальными изменениями и цифровизацией интересы граждан также подверглись трансформации.

Согласно концепции, разработанной Европейский судом по правам человека и закрепленной в ст. 1 Протокола № 1 к Конвенции о защите прав человека и основных свобод [1], у термина имущество имеется широкое толкование, которое позволяет относить к нему новые объекты, правовая природа которых не определена, но при этом, экономическая ценность которых очевидна и их можно с уверенностью считать активом.

Как отмечается в постановлении ЕСПЧ от 13.12.2011 «Концепция «имущества», имеет автономное значение, которое не ограничивается правом собственности в отношении материальных вещей и не зависит от формальной классификации по национальному законодательству: некоторые иные права и интересы, 
представляющие собой активы, могут также рассматриваться как «имущественные права» и, следовательно, как «имущество» [2].

У каждого вида цифровых прав имеется своя специфика, как следствие разработка общего правового режима не сможет наиболее полно учитывать их правовую природу и, как следствие не целесообразно.

Наиболее распространенные в обороте цифровые права, имеющие очевидную ценность это: токены, большие данные, аккаунты в социальных сетях, контент в цифровой форме и доменные имена.

В настоящее время «образ» компании формируется различными путями. В недавнем прошлом он отражался в логотипе, публикациях в печатных изданиях и различных видах рекламы. Коммуникация бизнеса с потребителем была трудной, последнему нужно было либо звонить на горячую линию, либо писать письма в главный офис, которые долго рассматривали.

Сейчас, у каждой компании есть веб сайт с формой обратной связи и аккаунты в социальных сетях, а самое главное сотрудник или даже целый отдел, который занимается коммуникацией с клиентами.

Количество способов рассказать о себе своим потребителям, сформировать нужный образ стремительно возросло. Помимо прочего, доля клиентов, которые приходят именно из интернета, из года в год стремительно увеличивается. Как следствие, средство коммуникации постепенно начинает превращаться в канал продаж.

В настоящее время множество компаний оказывает услуги по продвижению сайта или страниц в социальных сетях компании, услуг по формированию образа в сети интернет, главная цель которых - продажа продукции и услуг компании, а вовсе не создание образа или получение обратной связи от клиентов.

Помимо этого, большую ценность приобретает внимание аудитории. Ни для кого не секрет, что сейчас бюджет у рекламных кампаний в социальных сетях сопоставим, а в некоторых случаях превышает бюджет телевизионной рекламы. Человек в своем стремлении найти интересующую его информацию попадает в тематические группы в социальных сетях или аккаунты конкретных пользователей. В случае если ему важна эта информация, он продолжает следить за ее обновлением, периодически заходя и проверяя новости. За это внимание борются рекламодатели, для которых важно сообщить о своем продукте определённому кругу людей, которые с большей долей вероятности в нем заинтересованы.
В случае оценки бизнеса, в структуре которого большую роль играют веб сайт и аккаунты в социальных сетях в качестве канала продаж, оценке подлежит следующее:

- Аудиовизуальные произведения, произведения литературы и изобразительного искусства), составляющие контент;

- Средства индивидуализации (например логотип, доменное имя и пр.);

- База данных пользователей.

Принцип свободы договора позволяет как распорядится правом администрирования путем заключения сделки купли-продажи, так и передать это право в залог, для обеспечения исполнения обязательств.

Другим востребованным активом являются большие данные - массивы структурированной или неструктурированной информации о частных лицах (которая собирается в результате работы веб сайтов и мобильных приложений), либо промышленных данных (например данные о перевозках грузов различными видами транспорта).

Как было сказано выше, рекламодателям гораздо интереснее распространять информацию о своём продукте по целевой аудитории, нежели неопределенному кругу лиц. Большие данные, аккумулируемые, например поисковыми агрегаторами, банками (поисковые запросы, местонахождение, данные о покупках в интернет-магазинах и т.п.), позволяют гораздо лучше узнать о желаниях пользователей.

По мнению Санниковой Л.В. и Харитоновой Ю.С., немаловажную роль для современного бизнеса играет структуризация и последующий тщательный анализ информации о пользователях при помощи специально разработанных алгоритмов [3].

Оставляя за рамками настоящей работы вопросы конфиденциальности, можно с уверенностью утверждать, что большие данные, являются элементом, существенно повышающим эффективность канала продаж компании и как следствие прямо влияют на увеличение ее прибыли.

В следствии вышесказанного большие данные также можно считать существенным активом в деятельности современных компаний, который подлежит оценке наряду со средствами индивидуализации (веб сайтом и аккаунтом в социальных сетях). Уже есть компании, которые специализируются на создании, сборе и актуализации больших данных с целью их дальнейшей перепродажи и введения в гражданский оборот. Если база данных правомерно введена в оборот, имеет иму- 
щественную ценность (например на основании отчета об оценке), то почему она не может быть способом обеспечения исполнения обязательств?

База данных - это составное произведение, являющееся результатом творческого труда по подбору или расположению материалов (пп. 2 п. 2 ст. 1259 ГК РФ). В соответствии с ст. 1334 ГК РФ, изготовитель базы данных может распоряжаться своим исключительным правом. Согласно ст. 358.18 ГК РФ, исключительные права на результаты интеллектуальной деятельности могут быть предметом залога. Как указано в п. 3 ст. 1232 ГК РФ государственная регистрация залога исключительного права обязательна.

Складывающаяся судебная практика по этому вопросу противоречива. Как отмечает Ларионова В.А. суды не квалифицируют персональные данные в качестве объекта исключительного права [4].

Конституционный Суд Российской Федерации в своем определении указал, что «статья 128 ГК Российской Федерации, перечисляющая некоторые виды объектов гражданских прав и позволяющая суду в рамках дискреционных полномочий определять, относится ли к объектам гражданских прав то или иное благо, направлена на обеспечение интересов участников гражданского оборота» [5].

Стоит также отметить, что, исключительное право изготовителя базы данных получает правовую охрану только в момент завершения её создания (ст. 1335 ГК РФ), но с технической точки зрения представляется весьма сложным определить момент окончания работы по изготовления больших данных, так как им свойственно постоянное обновление.

Существуют точки зрения, согласно которым, для более точного определения больших данных необходимо разработка концепции нового нетрадиционного объекта интеллектуальной собственности [6]. При этом, сразу можно отметить, что этому мешает закрытый перечень объектов интеллектуальной собственности.

Как следствие судебная защита прав залогодержателя представляется трудоемкой и сопряжена с определенными рисками, вследствие чего рассматривать большие данные в качестве способа обеспечения исполнения обязательств в настоящий момент представляется затруднительным.

Наиболее интересным цифровым правом с точки зрения исследования из перечисленных выше является токен, который часто отождествляют с криптовалю- той, но это не совсем корректно, по причине того, что токен является родовым понятием.

Во-первых, криптовалюту получают посредством майнинга, а токены выпускаются при ICO (первичное размещение монет);

Во-вторых, первичный выпуск токенов осуществляется в большинстве случаев централизовано (за редкими исключениями) всем известным эмитентом. Криптовалюта выпускается только децентрализовано.

В-третьих, криптовалюта всегда создается на базе своего блокчейна, в то время как токен может существовать на чужом блокчейне (например, на самом распространенном в данный момент Ethereum);

Главное отличие токена от криптовалюты заключается в том, что последнюю можно использовать только как средство платежа, в то время как у токена могут быть различные назначения.

Эмитент токена может наделить его функцией как средства платежа, так и обязательством по выплате доли от прибыли компании. Токен может быть ключом, открывающим его обладателю какие-либо блага. Также к токену может быть привязан предмет из реального мира, благодаря чему с ним можно будет осуществлять сделки и фиксировать их в блокчейн сети.

Швейцарский орган по надзору за финансовым рынком (FINMA) в своем опубликованном исследовании занял позицию согласно которой, классические криптовалюты (Bitcoin, Ethereum) не наделяют их обладателей правом требования к эмитенту или третьему лицу [7].

Однако, учитывая отсутствие законодательного определения токена и судебных прецедентов в Швейцарии, в настоящее в качестве опоры используется разработанные FINMA в феврале 2018 «Руководящие принципы нормативной базы для ICO («FINMA ICO Guidelines») [8]. Разработанную в них классификацию, использует Швейцарский федеральный совет. Из нее можно выделить следующие категории токенов:

1. Платежные токены (которые, согласно FINMA, являются синонимом криптовалют) - предназначены для использования в качестве платежного средства для приобретения товаров или услуг или в качестве средства перевода денег или активов. Данные токены являются нематериальными активами. Примерами таких криптовалют являются Bitcoin (включая многочисленные криптовалюты, возникающие в результате форков или его вариаций, таких как Bitcoin Cash, Bitcoin Gold и Litecoin) и Ethereum; 
2. Служебные токены - предназначены для обеспечения цифрового доступа к приложению или услуге с помощью инфраструктуры на основе распределенного реестра;

3. Токены активов - представляют собой право требования или, например, долю в будущей прибыли компании или будущих потоках капитала. Таким образом, с точки зрения своей экономической функции такие токены аналогичны акциям, облигациям или деривативам. Токены, которые позволяют торговать физическими активами при помощи блокчейн-инфраструктуры, по мнению FINMA, также попадают в эту категорию.

8 октября 2019 года Швейцарский национальный банк заключил операционное соглашение с Банком международных расчетов (BIS) относительно расположенного в Швейцарии центра инновационного центра BIS.

Главная задача данного проекта - получить практические знания о соответствующих технологических разработках на основе технологии блокчейн, влияющих на задачи центральных банков.

В одном из исследовательских проектов в рамках этой инициативы тестируется интеграция технологии распределенного реестра в цифровые деньги центрального банка. Эта новая гибридная форма цифровых денег может позволить осуществлять расчеты токенизированных активов между финансовыми институтами. Данный проект реализуется в форме технико-экономического обоснования в рамках сотрудничества между Швейцарским национальным банком и компанией SIX [9].

Кроме того, налоговые органы некоторых кантонов (например Цуг) начнут принимать криптовалюты Bitcoin и Ethereum для налоговых платежей с 2021 года. Таким образом, кантон Цуг станет первым швейцарским кантоном, в котором налоги можно будет платить с помощью криптовалюты [10].

Размещенные на веб сайтах и в социальных сетях тексты, видео, аудиозаписи, фотографии и графика охраняются как результаты интеллектуальной деятельности. В силу привлечения к ним внимания аудитории они представляют имущественную ценность и являются активом для своего правообладателя.

С самого начала появления сети интернет, остро стоял вопрос борьбы с пиратством, в виду того, что в интернете ежедневно размещается огромные объемы информации, проконтролировать копирование и распространение которой не представляется возможным.
Как следствие, возникает необходимость в создании механизма обеспечения права собственности на цифровые объекты.

Платежные токены - взаимозаменяемы (биткоин который находится в кошельке одного пользователя равнозначен биткоинам в кошельках других).

Было разработано решение на основе технологии блокчейн - NFT (non-fungible token) - невзаимозаменяемые токены, существующие в единственном числе, подтверждающие цифровые права на нематериальные объекты (аудиовизуальные произведения, тексты, изображения, доменные имена и пр.).

Уникальность невзаимозаменяемых токенов обеспечивается записью информации при помощи смарт-контрактов - «способа заключения письменной сделки при помощи электронных либо иных технических средств, позволяющих воспроизвести на материальном носителе в неизменном виде содержание сделки».

Согласно ст. 309 ГК РФ «условиями сделки может быть предусмотрено исполнение ее сторонами возникающих из нее обязательств при наступлении определенных обстоятельств без направленного на исполнение обязательства отдельно выраженного дополнительного волеизъявления его сторон путем применения информационных технологий, определенных условиями сделки».

Технология блокчейн фиксирует информацию о правообладателе без возможности ее изменения или удаления. Таким образом становятся возможным ведение и контроль оборота цифровых прав.

Важно понимать какими правами обладают создатели и дальнейшие пользователи NFT токенов.

Например, токены активов предоставляют право на получение дивидендов, долю в компании, все это финансовые права. NFT не предоставляют подобных прав, хотя они предоставляют доступ к контенту или дают права на роялти.

Несмотря на то, что NFT уникальны в своем роде, они не предоставляют их держателям прав требования к эмитенту. Ими можно распоряжаться путем продажи, но не на открытых торговых площадках (Kraken, Bittrex, Bitstamp).

В настоящее время отсутствуют работы по анализу NFT как инструмента подтверждающего право интеллектуальной собственности. Проблема здесь заклю- 
чается в том, что владение NFT не означает владение оригинальной работой. Другими словами, покупка NFT не означает, что вы покупаете права интеллектуальной собственности на данный контент.

В соответствии с п. 1 ст. 1265 ГК РФ права автора «неотчуждаемы и непередаваемы, в том числе при передаче другому лицу или переходе к нему исключительного права на произведение и при предоставлении другому лицу права использования произведения. Отказ от этих прав ничтожен». То есть покупка произведения искусства не означает, что авторские права на произведение искусства переходят к покупателю.

С точки зрения авторского права NFT - это цифровое свидетельство. Убеждение покупателей относительно того, чем они владеют, не отражаются в правовой реальности. Более того, компании, оказывающие посреднические услуги, не всегда прозрачны.

Поскольку NFT не требует, чтобы люди действительно владели авторскими правами, это приводит к различного рода злоупотреблениям.

Уже несколько раз придавались публичной огласке случаи, когда на торговых площадках создавались аккаунты известных художников и продавались их работы и только в последствии выяснялось, что это мошенники [11]. В настоящее время система NFT основана на том, что люди, преобразовавшие цифровой объект в токен, являются настоящими авторами и действуют добросовестно.

На основных торговых площадках OpenSea и Rarible не нужно подтверждать, право авторства, перед тем как поместить цифровой объект в блокчейн. Но и подтвердить себя как автора, при этом не являясь им на самом деле тоже несложно. Процесс проверки площадки Rarible включает заполнение нескольких форм, которые, похоже, никто не проверяет. OpenSea вообще полностью отказалась от проверки. Теперь платформа рекомендует покупателям проводить собственное исследование.

Канадская компания Dapper Labs с целью борьбы с мошенниками создала специальную лицензию NFT для решения проблем с правами интеллектуальной собственности, присущих NFT. Это важный шаг вперед в информировании пользователей о том, что с помощью NFT они не покупают авторские права. Пользователи покупают только лицензионный контент.

Права собственности на цифровое искусство, добросовестно созданное в форме NFT, можно продавать на разных торговых площадках и рассматривать преимущества данной технологии:
Во-первых, NFT обеспечивают аутентичность цифрового права. В качестве уникального токена его можно использовать для пометки произведений искусства, своеобразной подписи. Токен не может заменить настоящую картину, но он может быть очень удобным инструментом в случае, если собственник решит передать ее в залог в качестве способа обеспечения исполнения своих обязательств. Картина в данном случае является хорошим примером, как правило для ее сохранности лучше не перемещать ее без серьезной на то необходимости, но в случае использования токена, займодавец может быть уверен в том, что право собственности на объект перейдет к нему автоматически при помощи смарт контракта и он сможет отслеживать местонахождение картины.

Во-вторых, технологию NFT используют художники, создающие цифровую графику - переосмысленные произведения искусства. Природа NFT как уникального токена, придает аутентичность цифровому искусству, которой не было до этого. С учетом постоянного бесконтрольного копирования информации в сети Интернет, это особенно актуально.

Например, Джек Дорси из Twitter, продал свой первый твит как NFT за более чем 2,9 миллиона долларов на платформе Valuables [12], которой управляет компания Cent - социальная сеть на основе блокчейна.

Твиттер, в котором говорится: «Просто настраиваю свой твиттер», был впервые опубликован Дорси 21 марта 2006 года. Дорси сообщил в Твиттере, что продаст свой первый твит, в последствии собрав миллионы долларов предложений от разных людей. Твит Дорси не имеет особой ценности, поскольку его могут подделать другие люди. Этот твит не был искусством, хотя он был подлинным, что подтверждается соответствующим невзаимозаменяемым токеном [13].

Платформа оpensea.io позволяет отслеживать переход права собственности на невзаимозаменяемые токены.

Благодаря посреднику компании NFTfi (одноранговая, децентрализованная, торговая площадка) стал возможным займ под залог цифровых прав как способ обеспечения исполнения обязательств. Компания дает возможность заемщикам передавать цифровые активы для получения ссуды, а кредиторам делать предложения о предоставлении ссуды и получать проценты.

На платформе происходит согласование существенных условий займа - его сумма, сумму погашения кредита и его продолжительность (сейчас доступны: 7, 30 или 90 дней). 
Как только пользователь предложит ссуду заемщику под залог цифрового права система изменит цвет NFT на синий. Нажатие на карточку актива означает принятие займа. Принятие предложения приводит к тому, что NFT заемщика будет заблокирован в смарт-контракте, а сумма займа будет автоматически перечислена в кошелек заемщика криптовалютой WETH. Далее NFT будет отображаться желтым цветом, что означает, что он находится в залоге.

Погашение займа происходит автоматически в соответствии с согласованным между сторонами графиком. В случае невыполнения обязательств заемщиком (отсутствия криптовалюты в его кошельке) право собственности на NFT переходит к кредитору автоматически.

Главная задача технологии децентрализованных реестров - исключение посредников. В случае выдаче займа под залог как цифровых прав, так и других активов, ключевое значение имеет обеспечение возврата денежных средств. Для этого необходимо в первую очередь правильно оценить предмет залога и, во-вторых, обеспечить его передачу займодавцу помимо воли заемщика, в случае нарушения исполнения обязательств.

Говоря об оценке, очевидно, что в случае кредитования на большую сумму, необходимо руководствоваться заключением оценщика, имеющего опыт проведения экспертиз и знающего специфику цифровых прав, деятельность которого в обязательном порядке должна быть застрахована, на сумму сопоставимую сумме займа.

Вместе с этим несмотря на правильную оценку предмета залога, не менее важным является механизм принудительной передачи цифрового права займодавцу. В настоящее время, компании, оказывающие посреднические услуги (Valuables NFTfi) находятся в зарубежных юрисдикциях и в случае возникновения конфликтной ситуации спор будет рассматриваться в суде того государства, где они зарегистрированы. Займодавец столкнется с очевидными трудностями, ввиду которых рассматривать NFT токены в качестве способа обеспечения исполнения обязательств перед российской компанией кредитором не представляется возможным.

В настоящее время принудительная передача цифровых прав возможна по отношению лишь к аккаунтам в социальных сетях и доменным именам, ввиду того что у них есть операторы, которые помогут это осуществить на основании решения суда.

Передача больших данных по решению суда взыскателю возможна, в случае если ее обладатель российское юридическое лицо, во владении которого находятся другие материальные активы. По отношению к нему можно применить, например судебную неустойку, в случае неисполнения решения суда в добровольном порядке.

Передача невзаимозаменяемых токенов, на основании вступившего в законную силу решения суда, в настоящее время не представляется возможным. Об этом можно будет говорить только в случае появления российского юридического лица, оказывающего посреднические услуги как это делают компании Valuables NFTfi, имеющего большой уставной капитал, учредители которого имели бы соответствующий опыт и вызывали доверие.

\section{ЛИТЕРАТУРА}

1. Протокол N1 к Конвенции о защите прав человека и основных свобод. 20 марта 1952 г. (с изменениями от 11 мая 1994 г.) ETS № 009. Париж // Европейская конвенция о защите прав человека. URL: http://www.echr.ru/index.asp (дата обращения: 23.05.2020)

2. Постановление ЕСПЧ от 13.12.2011 «Дело «Васильев и Ковтун (Vasilyev and Kovtun) против Российской Федерации» (жалоба N13703/04) http://www. consultant.ru/cons/cgi/online.cgi?req=doc\&base $=A R B 002 \& n=308531 \# 05017345371845461$ (дата обращения: 23.05.2020)

3. Санникова Л.В., Харитонова Ю.С. Цифровые активы как объекты предпринимательского оборота // Право и экономика. 2018. № 4 // СПС КонсультантПлюс

4. Ларионова В.А. Информационный брокер как новый субъект информационного права в эпоху Big Data // Право в сфере Интернета: Сборник статей. (рук. авт. кол. и отв. ред. М.А. Рожкова). М. Статут. 2018 // СПС Консультант Плюс

5. Определение Конституционного Суда РФ от 24.06.2014 N1350-0 «06 отказе в принятии к рассмотрению жалобы гражданина Гинеевского В.А. на нарушение его конституционных прав статьей 128 Гражданского кодекса Российской Федерации» URL: http://www.consultant.ru/document/cons_doc_ LAW_157829/

6. Сергеев А.П., Терещенко Т.А. Большие данные: в поисках места в системе гражданского права // Закон. 2018. № 11 // СПС КонсультантПлюс

7. Guide pratique pour les questions d'assujettissement concernant les initial coin offerings (ICO). Edition du 16 fevrier 2018 // FINMA. URL: https://www.finma. ch (дата обращения: 23.05.2020)

8. FINMA publishes ICO guidelines. URL: https://www.finma.ch/en/news/2018/02/20180216-mm-ico-wegleitung/ (дата 0бращение 23.05.2021)

9. SNB und BIZ unterzeichnen operative Vereinbarung zum BIZInnovation-Hub-Zentrum in der Schweiz. URL: https://www.snb.ch/de/mmr/reference/ pre_20191008/source/pre_20191008.de.pdf (дата обращения 23.05.2021) 
10. Canton Zug to accept cryptocurrencies for tax payment beginning in 2021. URL: https://www.bitcoinsuisse.com/news/canton-zug-accept-cryptocurrenciesfor-tax-payment-in-2021 (дата обращения 23.05.2021)

11. NFT mania is here, and so are the scammers URL: https://www.theverge.com/2021/3/20/22334527/nft-scams-artists-opensea-rarible-marble-cards-fraudart (дата обращения 23.05.2021)

12. Apparently you can actually sell your tweets as NFT URL: https://www.theverge.com/2021/3/5/22316320/jack-dorsey-original-tweet-nft-cent-valuables (дата обращения 23.05.2021)

13. Jack Dorsey tweet URL: https://v.cent.co/tweet/20 (дата обращения 23.05.2021)

\section{( ) Зюльков Дмитрий Сергеевич (dmitryzyulkov@gmail.com ).}

Журнал «Современная наука: актуальные проблемы теории и практики»



